\title{
Haiti One Year Later: Cuban Medical Team Draws on Experience and Partnerships
}

\author{
By Conner Gorry MA
}

Nearly a year ago on a day like today-as people scrabbled for some charcoal to cook the evening meal, fetched their children from school, and sewed costumes for carnival-the ground began to shift. Buildings folded and houses crumbled. In the time it takes to read this paragraph, one of the most devastating earthquakes recorded in the hemisphere changed the Haitian landscape forever. Twelve months on, quake survivors struggle to live, study, work, and worship within the parameters of this new landscape. They also struggle to stay healthy.

"It's important to be vigilant," Dr Jorge Pérez, deputy director of Cuba's Tropical Medicine Institute, told MEDICC Review in Port-au-Prince last March after assessing the post-quake health situation. "The epidemiological picture is going to get much more complicated."[1] On October 21, nine months after the earthquake that killed 250,000 and left over one million homeless, his prediction was borne out when the first cases of cholera were confirmed by the National Public Health Laboratory in Port-auPrince.[2] By November 19, the outbreak had spread to all 10 departments across the country. As of December 26, a total of 148,787 cases had been reported with 3,333 deaths, for a case fatality rate of $2.2 \%$.[3]

Cholera-a disease not seen in this Caribbean country for a century - "is now entrenched in Haiti and conditions on the ground are such that we should expect many more cases," reports Dr John Andrus, Deputy Director of the Pan American Health Organization (PAHO).[4]

Indeed, Haiti is now experiencing a full-blown cholera epidemic caused by Vibrio cholerae, challenging health care providers to develop strategies and response mechanisms to effectively contain the disease and protect the healthy population. Among those at the forefront of these efforts are the Cuban medical team and its international partners.

\section{Cholera Emerges}

Some of the first suspected cases occurred in Mirebalais, in Haiti's Centre department. Dr Adac Mendoza and Dr Yobana Carmenza, Nicaraguan and Colombian members, respectively, of the Cuban-led medical team, are posted at the Mirebalais Comprehensive Health Center, where an outbreak was identified on October 15. Both these doctors are among the graduates of Havana's Latin American Medical School (ELAM, its Spanish acronym) who joined Cuban health professionals in disaster relief efforts shortly after the quake.

Dr Mendoza told MEDICC Review that they became concerned when they saw a sudden rise in acute diarrhea patients of all ages presenting at the hospital. Within days, "we were thrust into a frightening scenario, as more patients arrived in different stages of dehydration, with frequent, watery diarrhea and vomiting. Some died of spontaneous cardiac arrest," said Dr Mendoza. "We began to suspect cholera."

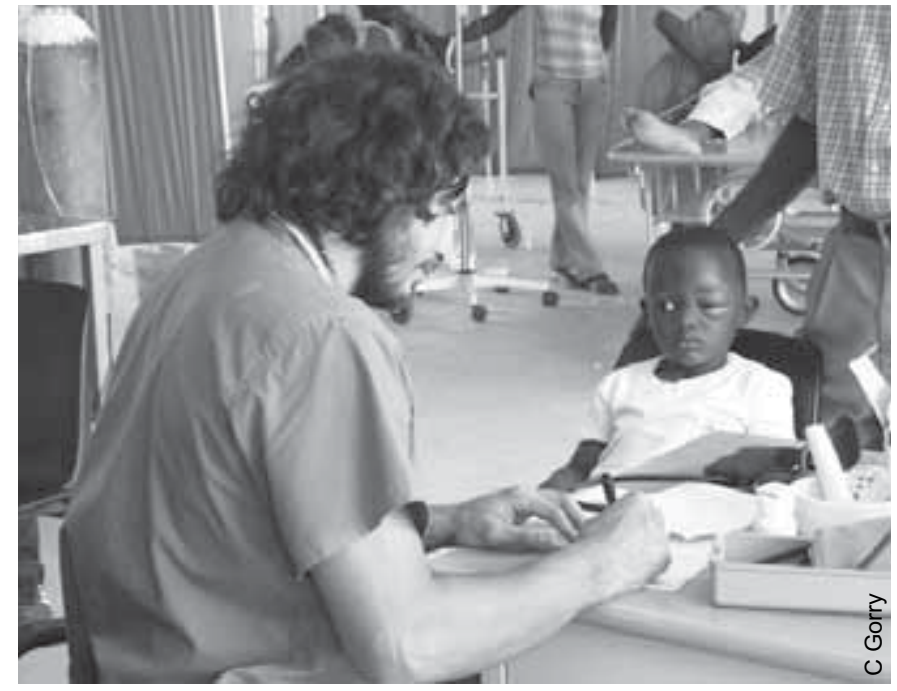

Dr Adac Mendoza, Latin American Medical School graduate from Nicaragua, pictured here treating earthquake survivors in the Haitian capital of Port-au-Prince. Last October, he was one of the doctors who suspected cholera cases in Mirebalais.

"There was a lot of confusion and fear during those first days. Things were disorganized and lack of coordination also created a bottleneck," Dr Mendoza explained. Scarcity of antibiotics, combined with the highly unsanitary living conditions that continue to plague Haiti, and the fact that cholera had not been seen in the country for generations, also complicated adoption of effective strategies.

\section{Coordinating Response, Maintaining Services}

Once cholera was confirmed, the Cuban medical team, which is a member of the Ministry of Health-PAHO/WHO Health Cluster coordinating the epidemic response, adopted international cholera treatment protocols and strict biosafety guidelines for all personnel, among other measures. This response also included establishing separate Cholera Treatment Centers (CTCs), smaller Cholera Treatment Units (CTUs) and Oral Rehydration Posts (ORPs), as well as relocation of resources-medicine, tents, equipment, and health staff-to those areas experiencing outbreaks. Health prevention messages in Creole were drafted and distributed, using every avenue, from sending cellular text messages to preaching prevention from church pulpits.[5]

Reinforcements from the Henry Reeve Emergency Medical Contingent arrived from Cuba in early December. Since 2005, the Contingent's specialists in disaster medicine and epidemics have been dispatched following disasters in countries such as Pakistan, China, Guatemala, Chile, and most recently Haiti. Within 24 hours of the January 2010 earthquake, the first Henry Reeve detachment arrived in Port-au-Prince to supplement the Cuban teams already working in Haitian public health facilities since 1998 under bilateral government agreements. When the post-disaster emergency phase officially ended last spring, the Cuban-led team of over 1000 
health professionals stayed to contribute to rebuilding Haiti's health system, including staffing of 30 comprehensive health centers, another 30 community referral hospitals and 30 rehabilitation centers.

Last October's arrival of fresh Henry Reeve detachments-including the Cuban specialists and doctors from 22 countries trained at ELAM-was important for several reasons. First, these health professionals are trained expressly for post-disaster contexts, to work in areas such as vector control, case management, and epidemiological surveillance.

Second, their incorporation increased the feasibility of maintaining cholera treatment centers separate from standard health care facilities-a strategy key to preventing transmission and maintaining hygiene and sanitary controls while continuing other services. "These reinforcements mean the Cuban doctors and other team members staffing community hospitals can continue their work uninterrupted," explains Dr Yiliam Jiménez, Director of Cuba's International Medical Cooperation. "So even though we're in the throes of an epidemic, these communities still have other health services they can count on."

Cuban Health Cooperation in Haiti (December 28, 2010)

\begin{tabular}{|c|c|}
\hline \multicolumn{2}{|l|}{ Infrastructure \& Staffing } \\
\hline $\begin{array}{l}\text { Members of Cuban-led medical } \\
\text { team in Haiti }\end{array}$ & 1398 \\
\hline $\begin{array}{l}\text { - ELAM-trained members } \\
\text { - Haitian ELAM-trained members } \\
\text { - Doctors } \\
\text { - Nurses }\end{array}$ & $\begin{array}{l}234 \\
152 \\
498 \\
464\end{array}$ \\
\hline Countries represented in team & $\begin{array}{l}23 \text { (Argentina, Bolivia, Chile, } \\
\text { Colombia, Congo, Cuba, } \\
\text { Dominican Republic, Ecuador, } \\
\text { El Salvador, Guatemala, Guinea } \\
\text { Bissau, Haiti, Honduras, Mali, } \\
\text { Mexico, Nicaragua, Nigeria, } \\
\text { Panama, Paraguay, Peru, } \\
\text { Saharawi Arab Democratic } \\
\text { Republic, United States, Uruguay) }\end{array}$ \\
\hline $\begin{array}{l}\text { Percent of team working in } \\
\text { cholera-affected areas }\end{array}$ & $61 \%$ \\
\hline $\begin{array}{l}\text { Number of cholera treatment } \\
\text { centers staffed by team }\end{array}$ & 59 \\
\hline \multicolumn{2}{|l|}{ Results } \\
\hline Cholera patients treated & 47,537 \\
\hline Cholera fatalities & 270 \\
\hline
\end{tabular}

Source: Brigada Médica Cubana en Haití. 28 December 2010; Port-au-Prince, Haiti.

\section{Experience Leads to Innovation}

A comprehensive program that has posted Cuban health professionals in Haiti's public health facilities since 1998-through hurricanes and floods, coups and quakes-includes 6-year scholarships for young Haitians to study medicine in Cuba. To date, 625 Haitians have graduated from Cuba's Latin American Medical School; some 430 of them are currently working in Haiti, the majority either in public hospitals or with the Cuban medical team itself.[6] The in-country experience accumulated by the Cubans over 12 years, combined with the indispensable cultural affinity brought by the team's Haitian members, has led to several new approaches since the earthquake and later cholera outbreak.

Given the severity of the quake and the matrix of adverse social determinants predating the disaster, the Cuban-led team undertook epidemiological surveillance activities almost immediately. These included tent-to-tent visits in displaced persons' camps, quadrant-by-quadrant camp mapping for more efficient case management and disease control, and follow-up with patients presenting with infectious disease symptoms at Cubanstaffed health facilities. These, however, were just first steps; it fast became evident that the situation required a coordinated surveillance system.

Thus, sentinel sites for epidemiological surveillance were established in hospitals and health centers around the country where the team was working. The sites have formed an epidemiological alert network, activated whenever there are outbreaks atypical to Haiti, enabling immediate notification of the Haitian Ministry of Public Health. "When our doctors in Mirebalais started seeing cases of acute diarrhea with cholera-like symptoms, the network notified the Haitian health authorities. Together with other medical NGOs and PAHO, we sent samples to the lab in Port-au-Prince, which confirmed that it was, in fact, cholera," Dr Jiménez told MEDICC Review.

A second strategy was set in motion during the cholera epidemic itself: active screening for new cases to save more lives through early detection and treatment. To achieve this in Haiti-where rural villages and settlements are often far from larger population centers, health posts, and even roads-the Cuban-led team divided into small mobile units that visit communities to find and treat cholera cases.[7] Equipped with medicines, oral rehydration salts, and health and hygiene messages in Creole, the doctors and nurses hike or ride (in transport provided by the World Food Program) to these remote areas. Participation of Haitian physicians in these units is vital to another aspect of their work: identification and training of community leaders to mobilize for cholera prevention and health promotion.

"[Such active screening] has proved to be an important and effective way to educate the public and help stop the disease from advancing so aggressively," Dr Jiménez told MEDICC Review. This is a major concern of the PAHO/WHO Haiti Health Cluster, which notes: "containing the epidemic in rural areas requires intense social mobilization and community work... including the establishment of brigades of community workers that can actively identify cases and promptly refer them to appropriate structures. These brigades should also help disseminate health promotion messages."[5] Moving forward, the Health Cluster estimates 30,000 community workers and volunteers need to be trained to pursue this health promotion campaign.[4]

Cluster advisors, including Cuban specialists and others, such as the US Centers for Disease Control, designed a plan to prepare for future emergencies consisting of three pillars of action: surveillance, alert and response, and coordination; this plan was adopted by the Haitian Ministry of Public Health and is currently being implemented. Dr Patrick Dely, a Haitian ELAM graduate working in the National Public Health Laboratory in Port-auPrince, said this initiative is sorely needed: "As an epidemiologist, I fear the possibility of other epidemics. The situation is very difficult."

\section{Triangular Cooperation: The 'New Normal'}

Natural disasters the magnitude of the Haitian earthquake galvanize global support-to date over US\$15 billion has 
been pledged to Haiti from scores of countries and international organizations. The funds that have arrived take the form of temporary shelters, human resources, building materials, medicines, and supplies. Following the earthquake, it became readily apparent that Haiti would need more than traditional aid packages and disaster relief, sparking innovation among some global donors. On March 30, for example, Haiti, Cuba, and Brazil signed a tripartite agreement to help rebuild the Haitian health system, with Brazil pledging US\$80 million and Cuba committing to providing human resources and expertise. Venezuela, meanwhile, is financing the construction of comprehensive health centers and community hospitals throughout the country staffed by the Cuban medical team-including the one at Mirebalais where the team first suspected cholera. In other initiatives, debt relief was extended to Haiti by the International Monetary Fund, the World Bank, the United States and others.

Triangular cooperation-donors pledging support for another nation's work in a disaster-stricken country-is playing a major role in the Cuba team's efforts in Haiti. Just 10 days after the earthquake, the Norwegian government signed an agreement with Cuba pledging US\$885,000 for supplies and medicines for Cuban medical relief and cooperation in Haiti. On October 28, a week after cholera was confirmed, Norway donated another US $\$ 850,000$; over two-thirds of those funds are earmarked for reconstruction of the Haitian health system and the remainder for the cholera effort.

"What attracted us to working with the Cubans is that they have good contacts in Haiti. They've been there since 1998, so they know what works and what doesn't," First Secretary of the Norwegian Embassy in Cuba Anne Heidi Kvalsøren told MEDICC Review. "It has been a really positive and transparent experience; everyone on the Cuban side has been very accessible and focused on getting the job done." Kvalsøren says there may be future opportunities for triangular cooperation with Cubalonger-term, sustainable health projects in Haiti for example, and regional disaster prevention.

By the end of 2010, nearly a dozen such 'triangular cooperation' agreements had been negotiated to support Cuba's health efforts in Haiti.

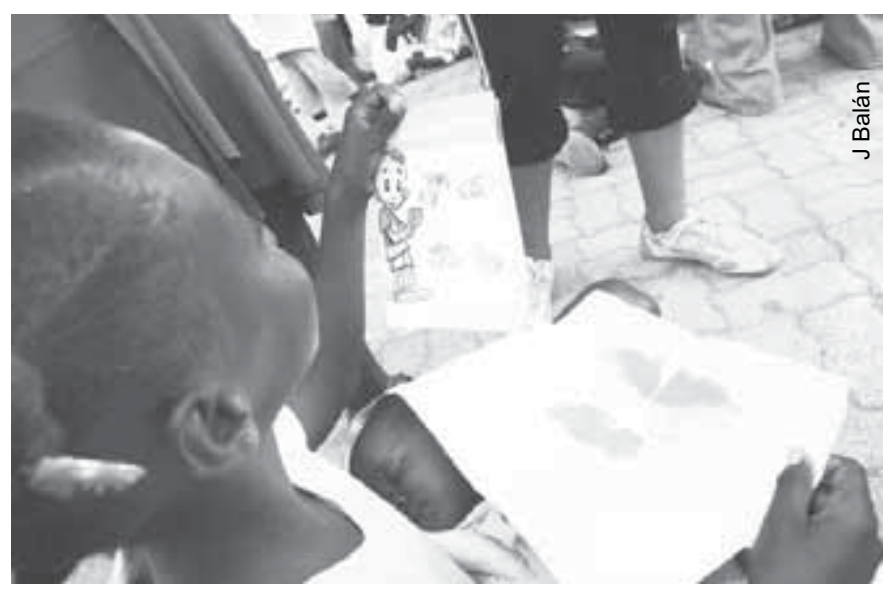

An art lesson comes with a public health message in a Cuban medical team outreach program.

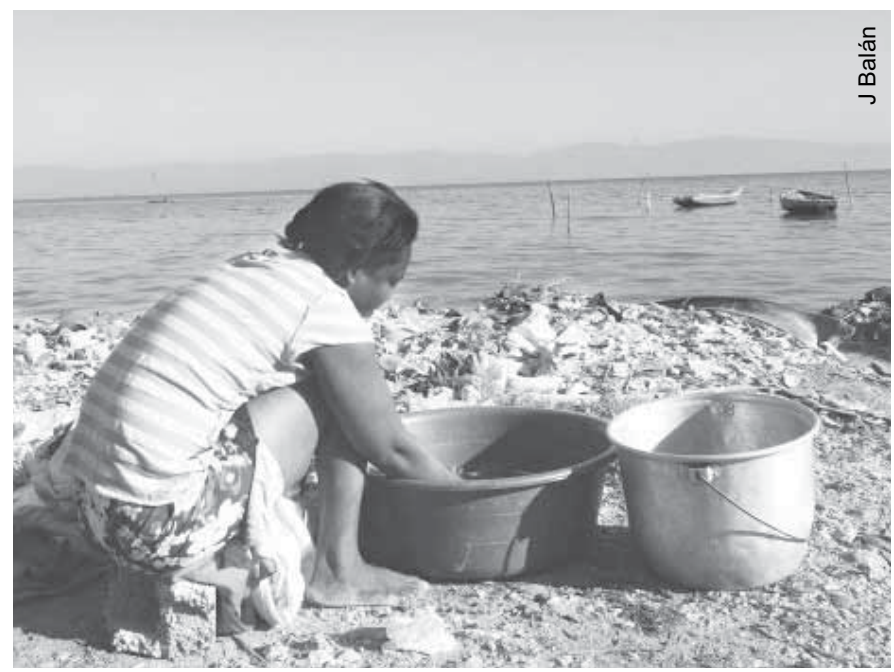

The waters of Haiti's Artibonite River: washing, bathing, cooking... and unsafe to drink.

\section{What Lies Ahead for Haiti and the Region}

Anyone who has even half an ear cocked to happenings in Haiti knows there's much more to be done. Dr Emiliano Mariscal, an ELAM graduate from Argentina who has been working with the Cuban medical team since February 2010, described conditions during a site visit to Mirebalais in late October: "We observed overcrowding, extremely poor housing conditions with small garbage dumps scattered throughout, malnutrition, helplessness, and resignation." Dr Mariscal emphasized the lack of potable water in the area, with residents using the contaminated Artibonite River for cooking, bathing, and drinking.[8]

These conditions in particular complicate cholera containment and prevention. Even before the earthquake, Haiti ranked 147 out of 147 countries on the Water Poverty Index-indicating lowest access to clean water.[9] A year after the catastrophe, there are 1.5 million people living in displaced persons' camps; of those, $40 \%$ have no access to clean drinking water and $30 \%$ have no access to toilets of any kind.[10] This sobering reality led PAHO to issue a blunt warning in its penultimate bulletin of 2010: "Unless water and sanitation improve," stated the organization, "it will not be possible to control the cholera outbreak."[11] At the end of December, PAHO reported that the Haitian government had begun chlorination of all public water systems, "a big advance for the country".[3]

Another problem facing medical responders is lack of supplies. Despite all the donations made and promised, Haiti is still facing critical shortages of oral rehydration salts and water purification tablets, intravenous rehydration solution, antibiotics, chlorine, body bags, personal protective equipment, cisterns, cholera beds, and materials for constructing latrines. All of these will be in increasing demand in the weeks and months to come since "the cholera strain responsible for the Haitian epidemic is associated with increased virulence, enhanced ability to survive in the environment and in a human host, and increased antibiotic resistance."[12] As a result, experts predict the number of cases could climb to 400,000 within 12 months.[4]

Cholera is a disease that can be spread transnationally, most commonly by infected travelers, but also through contaminated 


\section{International Cooperation Report}

commercial food imports. According to the US Centers for Disease Control, through December 18, there were 59 laboratoryconfirmed cases of cholera caused by Vibrio cholerae in the Dominican Republic and five in Florida. The CDC report warned that "more cholera cases associated with the current outbreak in Haiti are expected."[13]

This epidemiological reality is sounding the alarm across the region. It makes a strong argument for closer coordination and surveillance among neighboring countries-and for more sustained attention to Haiti itself, says Dr Jiménez: "Haiti requires much more attention from the international community, especially since this epidemic could spread, making it not just a Haitian problem. To achieve this, it's vital we work together beyond epidemic control, to help rebuild the country's health system." wh

This feature continues a series by Senior Editor Conner Gorry begun during her month-long assignment covering the Henry Reeve Contingent in and around Port-au-Prince in March 2010. For more, see Once the Earth Stood Still (MEDICC Review Vol. 12, Nos. 2 and 3), and MEDICC Field Notes: http://mediccglobal. wordpress.com.

\section{References \& Notes}

1. Gorry C. An ounce of prevention: Port-au-Prince vaccination campaign [homepage on the Internet]. Oakland (CA): MEDICC; 2010 Mar 13 [cited 2010 Dec 26]. Available from: www.mediccglobal.wordpress.com.

2. Centers for Disease Control and Prevention. Cholera confirmed in Haiti, October 21, 2010 [homepage on the Internet]. Atlanta (GA): CDC; 2010 Oct 22 [cited 2010 Dec 26]. Available from: www.cdc.gov/haiticholera/situation.

3. PAHO. Health Cluster Bulletin \#12. Cholera outbreak in Haiti: December 30, 2010. Port-au-Prince (HT): PAHO; 2010 Dec 30.

4. PAHO. Cases continue to climb, but fewer patients are dying from cholera homepage on the Internet]. Washington, DC: PAHO; 2010 Dec 2 [cited 2010 Dec 26]. Available from: http://new.paho.org/hq/index.php?option=com_conte nt\&task $=$ view\&id $=4518 \&$ Itemid $=1926$.

5. PAHO. Health Cluster Bulletin \#10. Cholera outbreak in Haiti: December 17 , 2010. Port-au-Prince (HT): PAHO; 2010 Dec 17

6. Brigada Médica Cubana en Haití. Cólera en Haití: Situación Actual. Port-auPrince (HT): Brigada Médica Cubana; 2010 Dec 28.

7. This mobile-unit modality was first used by the Henry Reeve Emergency Medical Contingent during their 6-month disaster relief mission in Pakistan following the October 2005 earthquake. The extreme Himalayan geography, combined with lack of transport and roads, often prevented patients from reaching field hospitals and health posts. In response, small Cuban teams of doctors and nurses went into the field daily, carrying medicines to treat people in small villages. See: Cuban doctors offering massive relief in Pakistan. MEDICC Review. 2006 Mar-pr;8(1):11-4. Available from: www.medicc.org/publications/ medicc_review/0406/top-story.html.

8. Mariscal E. What's happening in Haiti? [Unpublished memo]. Port-au-Prince (HT); 2010 Nov 4

9. Lawrence $P$, Meigh J, Sullivan $C$. The water poverty index: an international comparison. Staffordshire (UK): Keele University; 2003 Mar.

10. Institute for Justice \& Democracy in Haiti. "We've been forgotten:" Conditions in Haiti's displacement camps eight months after the earthquake. South Boston (MA); 2010 Sep 15.

11. PAHO. Health Cluster Bulletin \#11. Cholera outbreak in Haiti: December 23, 2010. Port-au-Prince (HT): PAHO. 2010 Dec 23.

12. Walton DA, Ivers LC. Responding to cholera in post-earthquake Haiti. N Engl J Med. 2010 Dec 9;364(1):3-5.

13. Morbidity and Mortality Weekly Report (MWWR). Update on cholera: Haiti, Dominican Republic, Florida, 2010. [monograph on the Internet]. Atlanta (GA): CDC; 2010 Dec 24 [cited 2011 Jan 6]. Available from: www.cdc.gov/mmwr/ preview/mmwrhtml/mm5950a1.htm?s_cid=mm5950a1_w. 